\title{
Colour Doppler Study of Umbilical Artery in Antenatal Women with Severe Preeclampsia and Foetal Outcome
}

\author{
Yadlapalli Indiramani*, V. Ratnakumari, B. Jyothirmayi \\ Obstetrics and Gynaecology, Niloufer Hospital, Hyderabad, India \\ Email: "indiramani97@gmail.com
}

Received 22 December 2015; accepted 21 February 2016; published 24 February 2016

Copyright (C) 2016 by authors and Scientific Research Publishing Inc.

This work is licensed under the Creative Commons Attribution International License (CC BY). http://creativecommons.org/licenses/by/4.0/

(c) (i) Open Access

\section{Abstract}

Hypertensive disorders are the most common medical complications of pregnancy $(7.15 \%)$. Doppler analysis of umbilical artery S/D ratio PI and RI, absent or reversal of EDV were evaluated and follow up results studied in severe preeclampsia women between 26 to 40 weeks. Doppler analysis of Uterine Artery and Middle Cerebral Artery is also studied. Doppler study guides in decision making and follows up in severe preeclampsia and guides in reducing perinatal morbidity and mortality. Period of Study: This is a prospective randomised study conducted at Niloufer Hospital for Women and Children Red Hills Hyderabad from September 2011 to June 2014. Material and Methods: 100 pregnant women with severe preeclampsia who attended Antenatal Out-Patient Department and got admitted in Emergency ward underwent Umbilical artery velocimetry by means of a Colour doppler vision (6000 Toshiba corp Tokyo Japan) using 3.5_5 MHZ Trasabdominal traducer. Results: Total number of 100 women were studied. In this 60 women had foetuses with abnormal umbilical artery flow velocimetry and 40 had normal umbilical artery flow velocimetry. The average birth weight and diagnosis to delivery interval were lower in foetuses with abnormal umbilical artery doppler. Admission to neonatal intensive care unit is high. The APGAR score at 1 minute is $<7$ in 20 women with abnormal umbilical artery doppler compared to 17 women with normal umbilical artery doppler. Compared to 32 women with normal umbilical artery doppler, the APGAR score is more than 7 in 31 women with abnormal umbilical artery Doppler. $P=0.639647$ and chi-square statistic $=0.2192$, the result is statistically not significant at p-value $<0.05$, implying that APGAR scores are not dependent on doppler findings alone. Conclusion: Doppler study guides obstetrician to assess the physiological status of the foetus and it helps in identifying the changes in the foetal circulation. This study suggests that doppler assessment of foe to placental circulation including umbilical artery is a better prognostic indicator in severe PE and helps in timely intervention. The foetuses with normal artery flow velocimetry area at a lower

\footnotetext{
${ }^{*}$ Corresponding author.
}

How to cite this paper: Indiramani, Y., Ratnakumari, V. and Jyothirmayi, B. (2016) Colour Doppler Study of Umbilical Artery in Antenatal Women with Severe Preeclampsia and Foetal Outcome. Open Journal of Obstetrics and Gynecology, 6, 129-135. http://dx.doi.org/10.4236/ojog.2016.62016 
risk of having poor APGAR score than those with abnormal velocimetry and NICU admissions are less with normal umbilical artery flow velocimetry. The average birth weight of neonates with abnormal umbilical artery was lower compared to neonates with normal umbilical artery velocimetry.

\title{
Keywords
}

\author{
Preeclampsia, Absent End Diastolic Flow, Intra Uterine Growth Retardation, Colour Doppler, \\ Umbilical Artery
}

\section{Introduction}

Hypertensive disorders are the most common medical complications of pregnancy (7.15\%) [1]. Preeclampsia is a multisystem disorder involving multiple organs resulting in disturbances in biological and haematological indices and impaired foetal growth and foetal hypoxia making it mandatory to adequately monitor the foetal well being. These disorders are a major cause of maternal mortality and morbidity (30\%). The incidence of severe preeclampsia ranges from $0.6 \%$ to $1.2 \%$ in western countries [2]. Preeclampsia $<37$ weeks and severe preeclampsia $<34$ weeks complicate $0.6 \%$ to $1.5 \%$ and $0.3 \%$ of pregnancies respectively. The likely hood of preeclampsia and preterm preeclampsia is substantially increased in women with history of preeclampsia, chronic hypertension [3]. Antenatal foetal surveillance is the corner stone of management aimed at reducing maternal and perinatal mortality and morbidity. The rate of adverse birth outcome remain several fold higher among women with early onset Preeclampsia $<34$ weeks gestation than late onset Preeclampsia. Doppler flow velocimetry is a good predictor in growth restricted foetus at risk of intrauterine compromise. It is also useful in high risk pregnancies with oligohydramnios. Several studies have shown the relation between abnormal umbilical artery doppler and perinatal outcome [4]. The purpose of the study is to show the foetal outcome in severe preeclamptic women with aid of colour doppler velocimetry.

\section{Material and Methods}

The prospective study included 100 pregnant women with severe preeclampsia between 26 weeks and 40 weeks. The study was conducted at Niloufer Hospital for women and children Red Hills, Hyderabad from September 2011 to June 2014. The inclusion criteria are Well documented length of pregnancy, Singleton pregnancy, Gestational age 26 weeks to full term gestation, Severe preeclampsia. The exclusion criteria are Threatened preterm labour, Wrong dates, Multi foetal gestation, HELLP syndrome congenital malformations. These women were referred from the peripheral hospitals who attended antenatal out-patient department or emergency labour ward underwent umbilical artery doppler velocimetry by means of a colour doppler vision 6000. Toshiba Corp, Tokyo, Japan using 3.5 to $5 \mathrm{MHZ}$ trans abdominal transducer. Informed consent was taken from each woman and ethical committee permission from the hospital is taken. These women underwent antenatal doppler examination of umbilical artery after 26 weeks. The findings at the time of $1^{\text {st }}$ examination were taken into consideration. Repeated doppler studies were performed whenever needed. Patients were examined in semi recumbent position. The recording was done in free floating loop of umbilical cord and doppler wave forms are recorded. Depending up on the doppler report and basic ultrasound reports like amniotic fluid index and estimated foetal weight report decision regarding brief prolongation of pregnancy for 48 hours is taken. Antenatal glucocorticoid administration in preterm severe preeclamptic woman is given if the woman remains stable. Mode of delivery is decided based on estimated foetal birth weight, amniotic fluid index and doppler wave forms whether abnormal or normal readings. The information regarding perinatal outcome was recorded including birth weight, number of foetal and perinatal deaths, admission to NICU and number of days in NICU and mode of delivery. The doppler indices during pregnancy are interpreted in the light of gestational age. The normal cut off for S/D ration is taken as less than 3.5 at 30 weeks and less than 3 a 40 weeks. Absent and diastolic velocity, reversed end diastolic velocity were considered as abnormal. Increase in diastolic flow in foetal MCA suggested brain sparing effect in asymmetric IUGR. 


\section{Observations and Results}

Images of colour doppler velocimetry are shown in Figure 1 and Figure 2.

The number of preterm births in increased resistance of umbilical artery doppler findings were 46 and 28 in normal umbilical artery doppler findings.

Analysis of other studies:

Pere-Joan Torres and co workers conducted prospective observational study to investigate the relation between abnormal umbilical artery doppler velocimetry and foetal outcome in hypertensive pregnancies. The absence of end diastolic velocity predicted low birth rate in $100 \%$ of pregnancies and foetal death in $66.6 \%$. All still births had absence of end diastolic velocity.

Malhotra, Neena and Co workers conducted a prospective study to evaluate the role of umbilical artery doppler in growth restricted fetuses. It included 70 pregnant women with growth restricted foetuses confirmed by ultra sound were followed up with doppler studies of the umbilical artery. The study group (Group 1) consists of 35 women with absent or reversed end diastolic flow. These were compared with equal number of controls (Group 2) where growth restricted foetuses had normal doppler wave forms. The perinatal mortality in Group 1 was $45.7 \%$ as opposed to 8.5 in group 2. In comparison with absent end diastolic flow, reversed end diastolic flow had more morbidities.

Foetal growth restriction was common in the study from Netherland by Ganzevoort and associates associated foetal growth restrictions with preeclampsia was $94 \%$.

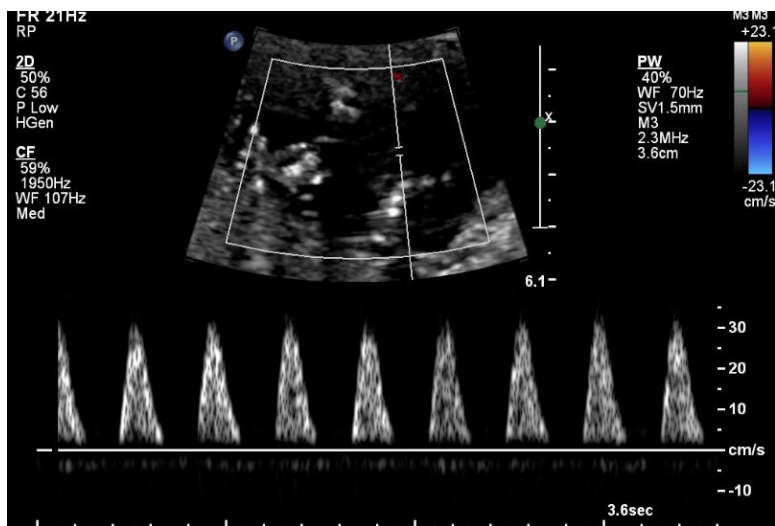

Umbilical artery - absent end diastolic flow

(a)

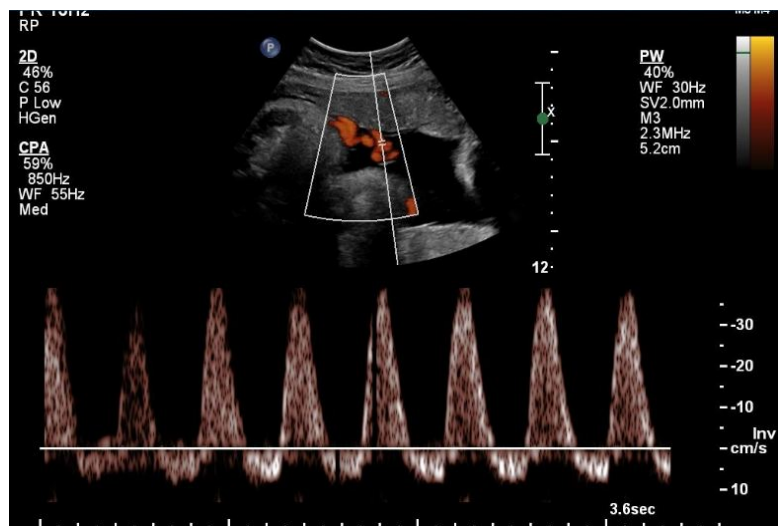

Umbilical artery - reversed diastolic flow

(b)

Figure 1. (a) Out of 60 women with abnormal umbilical artery doppler study, 18 women showed absent end diastolic flow; (b) out of 60 women, 4 have reversed diastolic flow in the women.

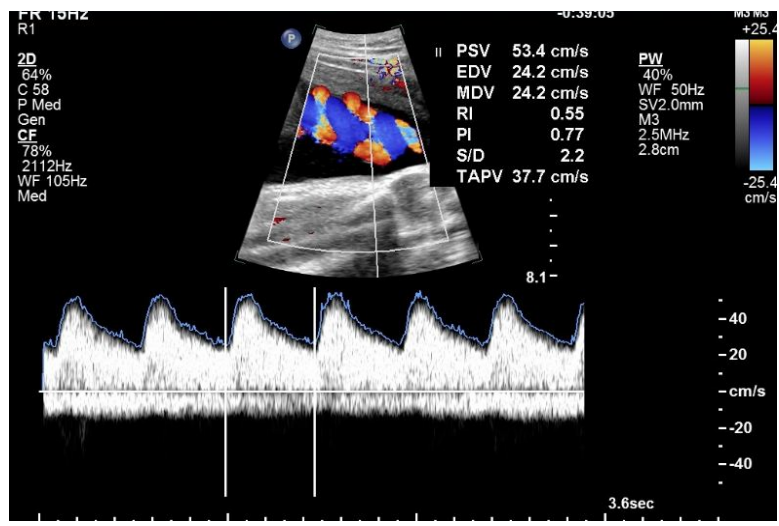

Umbilical artery - normal S/D ratio

(a)

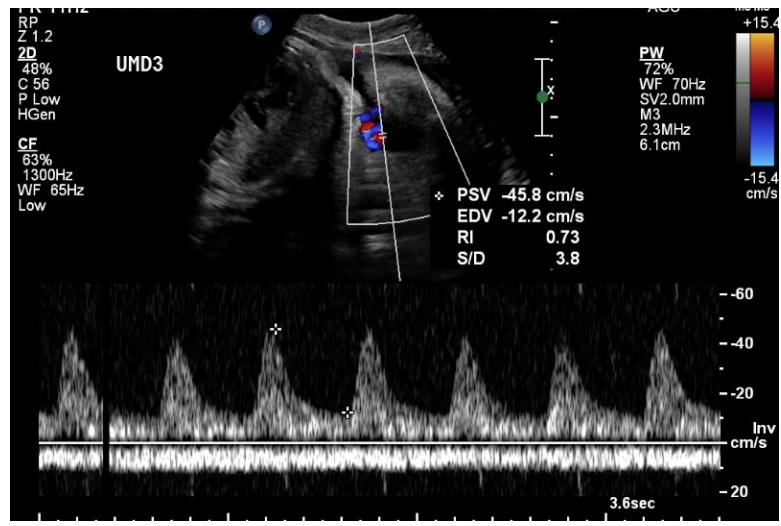

Umbilical artery - elevated S/D ratio

(b)

Figure 2. Cut off value for S/D ratio is taken as less than 3 to 3.5 from 34 weeks to term. From 28 to 34 weeks less than 4 is taken as normal. 42 women showed low end diastolic flow. 
Arora Devendra et al. studied the significance of umbilical artery doppler in growth restricted foetus and perinatal outcome. His findings regarding NICU admissions are $40 \%$ in normal doppler group and $70 \%$ in low end diastolic group and $100 \%$ in absent diastolic group.

Battaglia and Schuman et al. study of umbilical doppler in preeclampsia findings i.e., 92\%, $17 \%$ of elevated S/D ratio and absence of end diastolic flow respectively.

Mallikarjunappa et al. study of doppler changes in severe preeclampsia findings are $94 \%$ and $13 \%$.

\begin{tabular}{cccc}
\hline SD ratios & Battaglia et al. & Mallikarjunappa et al. & Our study \\
\hline Increased resistance & $87 \%$ & $94 \%$ & $70 \%$ \\
Absent end diastolic flow & $17 \%$ & $13 \%$ & $30 \%$ \\
\hline
\end{tabular}

\section{Discussion}

Hypertensive disorders complicating pregnancy cause maternal mortality and morbidity and foetal mortality and morbidity. The addition of Doppler testing to standard anteparturn foetal heart rate testing offers useful information to the clinician to aid the management of patient at risk for foetal compromise so that abnormal waveforms can be detected before the development of abnormalities noted on traditional foetal test like non stress test. The abnormal Doppler wave forms are either S/D ratio increased if it is $=3.5$ or absent or reversed end diastolic velocity in the umbilical artery indicates extremely increased placental vascular impedance. The observation of absent diastolic flow may occur nearly 8 days before pathologic cardiotocographic findings are present (Figure 1(a)). The appearance of reversed end diastolic flow is usually ominous and suggestive of imminent foetal death and indicates delivery if the foetus is salvageable (Figure 1(b)).

In our study of 100 pregnant women with severe preeclampsia umbilical artery Doppler S/D ratios were abnormal in $60 \%$ of cases and normal in $40 \%$ of cases. Figure 2(a) shows umbilical artery normal S/D ratios where as Figure 2(b) shows raised S/D ratios. In cases studied with abnormal UA Doppler there were 94\%, 20.37\% of cases with elevated S/D ratios, absent of end diastolic flow respectively in third trimester. These findings are consistent with BATTAGLIA AND SEHUMAN et al study of Umbilical Artery Doppler in severe preeclampsia finding i.e., 92\%, 17\% of elevated S/D ratio and absence of end diastolic flow respectively and also study conducted by Mallikarjunappa et al study of Doppler changes in preeclampsia findings are $94 \%$ and $13 \%$.

In our study of 100 pregnant women with severe preeclampsia, the following criteria were taken for delivery. Unstable maternal conditions/Worsening maternal condition (imminent signs) Abnormal foetal heart tracings. Severe foetal growth restriction. Oligohydramnios with AFI $<5$. Elevated Umbilical artery S/d ratios. Absent diastole or reversal of diastolic flow.

In pregnant women with gestational age 28 - 34 antenatal corticosteroid dose was administered to enhance the foetal lung maturity [5]. Induction of labour was done depending upon the UA Doppler report, ultrasonographic report and maternal condition. Mode of delivery is planned and individualised [6]. Close monitoring of blood pressure levels was done.

In our study of 100 cases, comparison of UA Doppler in women with severe preeclampsia, showed no significant difference in maternal age and parity (Table 1). Similarly majority of women in both groups delivered by caesarean section (56\% with abnormal and $77.5 \%$ with normal UA Doppler) with indication being mainly on foetal grounds, worsening maternal condition, oligohydromnios or abnormal UA Doppler findings.

Table 1. Maternal obstetric history of study population $(\mathrm{n}=100)$.

\begin{tabular}{ccc}
\hline & Normal UA Doppler $(\mathrm{n}=40)$ & Abnormal UA Doppler $(\mathrm{n}=60)$ \\
Mean maternal age & 24.6 years & 22.8 years \\
Primipara & $20(50 \%)$ & $27(55 \%)$ \\
Multipara & $20(50 \%)$ & $16(26.6 \%)$ \\
Previous history of pre-exlampsia or eclampsia & $5(12.5 \%)$ & $6(10 \%)$ \\
Previous history of perinatal death & Nil & \\
\hline
\end{tabular}


A total of 70 cases (p-value $=0.001)$ are associated with antenatally detected IUGR, of which 19 were with normal Doppler without associated antenatally detected IUGR and 11 were with abnormal Doppler without associate clinically suspicious IUGR (Table 2). Depending on the mode of delivery, one minute APGAR score varied with $p$-value $p<0.05$. In considering vaginal delivery one minute APGAR score relation p-value is significant $\mathrm{p}=0.037$. Intra partum foetal heart rate variability was observed in some cases. Low birth weight babies $<2.5 \mathrm{~kg}$ may be due to intrauterine growth restriction or constitutionally small foetuses [7]. Small for gestational age babies with abnormal Doppler have shorter duration of diagnosis to delivery interval (Table 3). Abnormal umbilical artery wave forms were associated with low birth weight babies $\mathrm{p}=0.0022$. Incidence of oligohydramnios is also more (Table 4). Foetuses with abnormal Doppler and oligogydramnios were delivered by caesarean section (Table 5). These foetuses which delivered vaginally with abnormal UA Doppler have lower birth weight percentiles with higher perinatal asphyxia in terms of lower APGAR scores $<7$ at birth, $p=0.037$ (Table 6). The need for positive pressure ventilation was more for foetuses with absent end diastolic flow.

Table 2. Correlation of antenatally diagnosed IUGR with UA doppler.

\begin{tabular}{ccc}
\hline Iugr clinically & Abnormal UA Doppler N $=60$ & Normal doppler $\mathrm{N}=40$ \\
\hline Present & $51(85 \%)$ & $19(47.5 \%)$ \\
Absent & $11(18.3 \%)$ & $19(47.5 \%)$ \\
\hline
\end{tabular}

Chi square $\mathrm{x}^{2}=11.674, \mathrm{df}=1, \mathrm{p}=0.001$, statistically significant at $\mathrm{p}$-value $<0.05$. Clinically diagnosed IUGR is mostly associated with abnormal UA Doppler findings.

Table 3. Umbilical artery doppler findings in relation to gestation age of onset.

\begin{tabular}{ccc}
\hline Gestational age in weeks & Normal UA Doppler & Abnormal UP Doppler \\
\hline $26-34$ & 14 & $32(69 \%)$ \\
$35-40$ & 26 & 28 \\
\hline
\end{tabular}

In early onset severe preeclampsia, 69\% cases have abnormal doppler umbilical artery findings.

Table 4. Umbilical artery doppler findings and association with oligohydraminos.

\begin{tabular}{ccc}
\hline Oligohydraminos & Abnormal UA Doppler & Normal umbilical artery doppler \\
\hline Present & 41 & 18 \\
Absent & 19 & 22 \\
\hline
\end{tabular}

Chi square statistic $\mathrm{x}^{2}=5.4017, \mathrm{p}=0.02$, $\mathrm{p}$-value is statistically significant at $\mathrm{p}<0.05$. Abnormal $\mathrm{UA}$ Doppler is associated with oligohydramnios.

Table 5. Modes of delivery.

\begin{tabular}{|c|c|c|c|c|}
\hline \multirow{2}{*}{ Gestational age in weeks } & \multicolumn{2}{|c|}{ Abnormal UA Doppler } & \multicolumn{2}{|c|}{ Normal UA Doppler } \\
\hline & LSCS & Vaginal & LSCS & Vaginal \\
\hline $25-34$ & 11 & 17 & 7 & 6 \\
\hline $35-40$ & 29 & 3 & 24 & 3 \\
\hline
\end{tabular}

Chi square statistics $\mathrm{x}^{2}=13.9, \mathrm{x}^{2}=7.3 \mathrm{p}=0.0001, \mathrm{p}=0.006$ Abnormal and normal group respectively. Statistically significant at $\mathrm{p}$ value $<0.05$.

Table 6. Relationship between perinatal deaths and umbilical artery doppler flow velocimetry changes.

\begin{tabular}{ccc}
\hline & Normal umbilical artery doppler & Abnormal umbilical artery doppler \\
\hline IUD & 0 & 14 \\
Still birth & 1 & 7 \\
Early neonatal deaths & 0 & 0 \\
\hline
\end{tabular}

Chi square statistic $\mathrm{x}^{2}=7.7647, \mathrm{p}=0.005328, \mathrm{p}<0.05$, statistically significant signifying that abnormal UA Doppler findings are associated with increased perinatal morality. 
Table 7. Neonatal outcome.

\begin{tabular}{|c|c|c|c|c|}
\hline & \multirow{2}{*}{$\begin{array}{c}\text { Normal } \\
\text { UA Doppler } \\
\mathrm{N}=40(40 \%)\end{array}$} & \multicolumn{2}{|c|}{ Abnormal UA Doppler } & \multirow[b]{2}{*}{ p-value } \\
\hline & & $\begin{array}{l}\text { Low end distolic flow } \\
\qquad \mathrm{N}=42(70 \%)\end{array}$ & $\begin{array}{l}\text { AEDL/REDF } \\
\mathrm{N}=18(30 \%)\end{array}$ & \\
\hline Delivery at $<36$ weeks GA & $28(72 \%)$ & $33(78 \%)$ & $13(72.2 \%)$ & \\
\hline Non stress test & $5(12.5 \%)$ & $6(14.2 \%)$ & $6(33.3 \%)$ & \\
\hline $\begin{array}{l}\text { Diagnosis of abnormal UA Doppler } \\
\text { to delivery interval }\end{array}$ & 1 day & 2 day & 0 day & \\
\hline Average birth weight & $1.98 \mathrm{~kg}$ & $1.38 \mathrm{~kg}$ & $0.79 \mathrm{~kg}$ & 0.001 \\
\hline NICU admission at birth & $14(35 \%)$ & $18(42.86 \%)$ & $6(33.3 \%)$ & 0.011 \\
\hline APGAR $<7$ ( 1 minute) in $\geq 1 \mathrm{~kg}$ & 12 & 11 & 4 & 0.7 \\
\hline Perinatal deaths & 1 & 6 & 15 & 0.005 \\
\hline
\end{tabular}

Fetal outcome: reterm births $(<36$ weeks $)=74$.

Babies with abnormal umbilical artery doppler were more likely to get admitted to the neonatal intensive care unit and spend longer time in NICU (Table 7). In our study overall 35\% $(n=40)$ of patient with increased and AEDF Doppler were admitted to NICU [8]. The perinatal morbidity and mortality are more with abnormal umbilical artery Doppler group $(\mathrm{p}=0.005)$. There are increased NICU admissions with abnormal Doppler $\mathrm{p}$-value $<0.05$.

\section{Conclusion}

Doppler velocimetry studies of umbilical artery can provide obstetrician an important information regarding foetal well being to improve the foetal out come. Our data indicates that abnormal umbilical artery Doppler is associated with more oligohydramnios, low birth weight babies with more NICU admissions when compared to women with normal UA Doppler findings. Women with umbilical artery waveforms showing absence of diastolic flow are more likely associated with oligohydramnios, very low birth weight babies, are number of NICU admissions and perinatal deaths when compared to others.

\section{Disclosure}

We have neither any relationship nor financial interest with any companies in performing this study.

\section{References}

[1] Sibai, B., Dekker, G. and Kupfermic, M. (2005) Preeclampsia. Lancet, 365, 785-799 (Level III).

[2] Kuklina, E.V., Aya, C. and Callaghan, W.M. (2009) Hypertensive Disorder and Severe Obstetric Morbidity in the United States. Obstetrics \& Gynecology, 113, 1299-1306 (Level II-3).

[3] Catov, J.M., Ness, R.B., Kip, K.E. and Olsen, J. (2007) Risk of Early or Severe Preeclampsia Related to Pre Existing Conditions. International Journal of Epidemiology, 36, 412-419 (Level II-3).

[4] American College of Obstetricians and Gynaecologists (2002) Diagnosis and Management of Preeclampsia and Eclampsia: AOOG Practice Bulletin No. 33. Obstetrics \& Gynecology, 99, 159-167 (Level III). http://dx.doi.org/10.1016/S0029-7844(01)01747-1

[5] DeGarcia, P., Montufar-Bueda, I. and Fluiz, J. (2903) Expectant Management of Severe Preeclampsia between 24 and 34 Weeks' Gestation. European Journal of Obstetrics \& Gynecology and Reproductive Biology, 167, $24-27$ (Level II-2).

[6] Sibai, B.M. and Barton, J.B. (2007) Expectant Management of Severe Preeclampsia Remote from Term: Patient Selection, Treatment and Delivery Indications. American Journal of Obstetrics and Gynecology, 196, 514e1-9 (Level II-2).

[7] Vergani, P., Roncaglia, N., Andreotti, C., Arreghini, A., Teruzzi, M., Peruzzi, M., Pezzullo, J.C., et al. (2002) Prognostic Value of Uterine Artery. Doppler Velocimetry in Growth-Restricted Fetuses Delivered Near Term. American Journal of Obstetrics and Gynecology, 187, 932-936. http://dx.doi.org/10.1067/mob.2002.127137 
[8] Vossbeck, S., de Camargo, O.K., Grab, D., Bode, H. and Pohlandt, F. (2001) Neonatal and Neuro Developmental Outcome Infants Born before 30 Weeks of Gestation with Absent or Reversed End Diastolic Flow Velocities in the Umblical Artery. European Journal of Pediatrics, 160, 128-134. http://dx.doi.org/10.1007/s004310000680 